\title{
The Coexistence of Hypertension and Dyslipidemia in a Cohort of Iraqi patients with essential Hypertension: Cross Sectional Study
}

\author{
Ali Fawzi Abdalsahib Al Zamili*, Alaa Abdulabbas Hamza and Mohamed Ali H Hamed \\ Department of Medicine, Al-Diwaniyah Teaching Hospital, Iraq
}

*Corresponding author: Ali Fawzi Abdalsahib Al Zamili, Physician, Al-Diwaniyah teaching hospital, Department of Medicine, AlDiwania, Iraq.

To Cite This Article: Ali Fawzi Abdalsahib. The Coexistence of Hypertension and Dyslipidemia in a Cohort of Iraqi patients with essential Hypertension: Cross Sectional Study. Am J Biomed Sci \& Res. 2019 - 3(1). AJBSR.MS.ID.000626. DOI: 10.34297/AJBSR.2019.03.000626

Received: April 19, 2019 | Published: May 14, 2019

\begin{abstract}
Background: Hypertension and hyperlipidemia are among major risk factors for ischemic heart disease, the principal human killer worldwide. In addition, they form important components of the well-established metabolic syndrome. Generally speaking, dyslipidemia comprises abnormality in the level of triglyceride, HDL-cholesterol and LDL-cholesterol. The description of hypertension and dyslipidemia as a single entity under the title "dyslipidemic hypertension (DH)" has emerged in medical literatures since 1988; a suggestion was made at that time as being a genetic syndrome to explain the coexistence of dyslipidemia and essential hypertension in a subset of patients.
\end{abstract}

Aim of the study: To estimate the prevalence rate of co-existence of dyslipidemia and hypertension in a cohort of Iraqi patients with essential hypertension.

Patients and methods: The present cross-sectional study included 183 patients with essential hypertension who have sought medical advice for treating hypertension in Al-Diwaniyah Teaching hospital / Medicine consultation Unit. The study extended from January 2018 through January 2019. Variables included in the current study were age, gender, systolic and diastolic blood pressure, serum lipid profile, history of IHD and diabetes mellitus (DM) and family history of dyslipidemia.

Results: High proportion of patients with essential hypertension have in addition dyslipidemia accounting for 106 out of 120 (approximately $88 \%$ ). There was significant association between coexistence of hypertension and dyslipidemia and gender or age of patients ( $P>0.05)$; in addition, there was no significant association between other co morbidities such as IHD, diabetes mellitus and thyroid disorders and the coexistence of hypertension and dyslipidemia $(\mathrm{P}>0.05)$.

Conclusion: the prevalence rate of simultaneous occurrence of dyslipidemia and hypertension is common in our community and there should be a program to detect those patients because higher risk of morbidity and mortality in such patients.

Keywords: Dyslipidemia; Hypertension; Coexistence

\section{Introduction}

Hypertension and hyperlipidemia are among major risk factors for ischemic heart disease, the principal human killer worldwide. In addition, they form important components of the well-established metabolic syndrome [1,2]. Generally speaking, dyslipidemia comprises abnormality in the level of triglyceride, HDL-cholesterol and LDL-cholesterol [3]. The description of hypertension and dyslipidemia as a single entity under the title "dyslipidemic hypertension (DH)" has emerged in medical literatures since 1988 [4]; a suggestion was made at that time as being a genetic syndrome to explain the coexistence of dyslipidemia and essential hypertension in a subset of patients [5]; however, sporadic forms of DH are far more frequent than familial ones [1]. It has been reported that in addition to hypertension, another cardiovascular risk factor is present in the majority of hypertensive patients and that hyperlipidemia forms substantial proportion of these additional risk factors [6].

The interplay between hypertension and dyslipidemia when happen in the same patient is synergistic so that the risk will be far more significant that the risk encountered when either risk factor exists alone or when the individual risks are added together [7]. Indeed, this formed the rationale for risk stratification when dealing with patients complaining of ischemic heart disease (IHD) [8]. In 
the United States, reports about the coexistence of hypertension and dyslipidemia indicate prevalence rates between $15 \%$ up to $31 \%$ [9,10]. "Chennai Urban Population Study (CUPS study 5)" estimated the prevalence rate of coronary artery disease in south Indian patients with type 2 DM. In CUPS study 5, Patients with multiple risk factors had the highest prevalence rate of coronary artery disease (21.1\%); in order of frequency these risk factors were "diabetes, dyslipidemia, and hypertension"; nevertheless data on the concomitant existence of hypertension and dyslipidemia, in these diabetic patients, was not highlighted [11]. Actually, the reporting of coexistence of hypertension and dyslipidemia has been ignored by several other important studies $[12,13]$.

The rarity of Iraqi studies concerning the coexistence of dyslipidemia and hypertension justify the planning and conductance of the current study aiming at highlighting this problem and its association with overall cardiovascular risk.

\section{Patients and Methods}

The present cross-sectional study included 183 patients with essential hypertension who have sought medical advice for treating hypertension in Al-Diwaniyah Teaching hospital / Medicine consultation Unit. The study extended from January 2018 through January 2019. Variables included in the current study were age, gender, systolic and diastolic blood pressure, serum lipid profile, history of IHD and diabetes mellitus (DM) and family history of dyslipidemia. The study was approved by the institutional approval committee and verbal consent was obtained from all enrolled patients following detailed explanation of the aim and procedures of the current study. Data were transferred into an SPSS spread sheet (version 23). Data presentation was in the form of mean, standard deviation, range, number and percentage. Student t-test was carried out to evaluate difference in mean between two groups whereas chi-square test was used to study association between categorical variables. The level of significance was considered at $\mathrm{P}$ $\leq 0.05$.

\section{Results}

The present study included 120 patients with essential hypertension divided according to serum lipid profile into two groups, 106 patients with dyslipidemia and 77 patients without dyslipidemia. There was no significant difference in the distribution of patients according to gender $(\mathrm{P}=0.866)$. Means age of patients within the two groups were $54.03 \pm 12.69$ years and $51.27 \pm 10.40$ years and the difference was statistically insignificant $(\mathrm{P}=0.109)$. Mean systolic blood pressure was $156.23 \pm 28.10 \mathrm{~mm} \mathrm{Hg}$ and 153.54 $\pm 27.26 \mathrm{~mm} \mathrm{Hg}$ in patients without and patients with dyslipidemia, respectively and the difference was insignificant $(\mathrm{P}=0.515)$. Mean diastolic blood pressure was $94.87 \pm 13.15 \mathrm{~mm} \mathrm{Hg}$ and 92.59 $\pm 12.50 \mathrm{~mm} \mathrm{Hg}$ in patients without and patients with dyslipidemia, respectively and the difference was insignificant $(P=0.236)$. Mean serum cholesterol, mean serum triglyceride and mean serum LDH were significantly higher in dyslipidemia group than no dyslipidemia group ( $\mathrm{P}<0.001$ ), whereas, mean serum HDL was significantly lower in dyslipidemia group than non dyslipidemia group $(\mathrm{P}<$ 0.001). There was no significant difference in the distribution of patients according to family history of dyslipidemia, as shown in Table 1. There was no significant association between dyslipidemia and other chronic disorders including diabetes mellitus, ischemic heart disease, thyroid disease and renal failure (Table 2).

\begin{tabular}{|c|c|c|c|c|}
\hline \multicolumn{2}{|c|}{ Characteristic } & \multirow{2}{*}{$\begin{array}{c}\text { Without dyslipidemia } \\
\mathbf{n = 7 7} \\
30(39.0)\end{array}$} & \multirow{2}{*}{$\begin{array}{l}\text { With dyslipidemia } \\
\qquad \mathbf{n = 1 0 6} \\
40(37.7)\end{array}$} & \multirow{2}{*}{$\begin{array}{c}\mathbf{P} \\
0.866 \dagger\end{array}$} \\
\hline$S_{-}$ & Male, n (\%) & & & \\
\hline पетиет & Female, n (\%) & $47(61.0)$ & $66(62.3)$ & NS \\
\hline \multirow{2}{*}{ Age } & Mean \pm SD & $54.03 \pm 12.69$ & $51.27 \pm 10.40$ & $0.109 *$ \\
\hline & Range & $24-82$ & $22-75$ & NS \\
\hline \multirow{2}{*}{ SBP } & Mean \pm SD & $156.23 \pm 28.10$ & $153.54 \pm 27.26$ & $0.515 *$ \\
\hline & Rsange & $120.00-280.00$ & $120.00-230.00$ & NS \\
\hline \multirow{2}{*}{ DBP } & Mean \pm SD & $94.87 \pm 13.15$ & $92.59 \pm 12.50$ & $0.236 *$ \\
\hline & Range & $80.00-160.00$ & $80.00-140.00$ & NS \\
\hline \multirow{2}{*}{ Cholesterol } & Mean \pm SD & $157.56 \pm 28.23$ & $218.80 \pm 43.35$ & $<0.001 *$ \\
\hline & Range & $58.00-191.00$ & $117.00-365.00$ & HS \\
\hline \multirow{2}{*}{ Triglyceride } & Mean \pm SD & $117.13 \pm 37.07$ & $292.56 \pm 131.34$ & $<0.001 *$ \\
\hline & Range & $62.00-194.00$ & $110.00-879.00$ & HS \\
\hline \multirow{2}{*}{ LDL } & Mean \pm SD & $103.94 \pm 15.90$ & $120.13 \pm 30.70$ & $<0.001 *$ \\
\hline & Range & $82.00-132.00$ & $21.00-193.00$ & HS \\
\hline \multirow{2}{*}{ HDL } & Mean \pm SD & $29.66 \pm 5.11$ & $34.34 \pm 8.00$ & $<0.001 *$ \\
\hline & Range & $24.00-43.00$ & $21.00-49.00$ & HS \\
\hline \multirow{2}{*}{$\begin{array}{l}\text { Family history of } \\
\text { dyslipidemia }\end{array}$} & Positive & $1(1.3)$ & $1(0.9)$ & $1.000 ¥$ \\
\hline & Negative & $76(98.7)$ & 105 (99.1) & NS \\
\hline
\end{tabular}




\begin{tabular}{|c|c|c|c|c|c|}
\hline \multirow{2}{*}{ Table 2: Associations with other diseases. } \\
\hline \multirow{2}{*}{ Other disease } & $\begin{array}{c}|c| \\
\text { Without } \\
\text { dyslipidemia } \\
\mathrm{n}=77\end{array}$ & \multicolumn{2}{|c|}{$\begin{array}{c}\text { With dyslipidemia } \\
\mathrm{n}=106\end{array}$} & \multirow{2}{*}{ P } \\
\cline { 2 - 5 } & $\mathrm{n}$ & $\%$ & $\mathrm{n}$ & $\%$ & \\
\hline IHD & 1 & 1.3 & 1 & 0.9 & $\begin{array}{c}1.000 ¥ \\
\text { NS }\end{array}$ \\
\hline Hypothyroidism & 1 & 1.3 & 1 & 0.9 & $\begin{array}{c}1.000 ¥ \\
\text { NS }\end{array}$ \\
\hline Hyperthyroidism & 0 & 0 & 1 & 0.9 & $\begin{array}{c}1.000 ¥ \\
\text { NS }\end{array}$ \\
\hline Renal failure & 0 & 0 & 1 & 0.9 & $\begin{array}{c}1.000 ¥ \\
\text { NS }\end{array}$ \\
\hline
\end{tabular}

\section{Discussion}

The present study showed that large proportion of patients with essential hypertension in our community has in addition the problem of dyslipidemia, 106 out of 120 accounting for approximately 88\%. The coexistence of hypertension and dyslipidemia is also common in other communities worldwide. The prevalence rate of "lipitension" in elderly US population is estimated to be $31 \%$. In another report, the overall prevalence of hypercholesterolemia alone, hypertension alone and lipitension was 18, 47 and $30 \%$, respectively. It was found also in American studies that the incidence rate of lipitension was significantly more in women than in men, $20 \%$ versus $16 \%$ [14]; however, in the present study there was no significant predilection for particular gender with respect to lipitension. It has been found that lipitension is more significantly associated with other co morbidities than hypertension alone [14]; however, the current study revealed no such association. Hypertension and Dyslipidemia are well recognized risk factors for cardiovascular disorders, and the simultaneous presence of both these conditions has been shown to be associated with additive risk [15]. Simultaneous presence of these conditions is variable worldwide. Studies have demonstrated that the interaction between these two conditions happens at the level of the vascular endothelial layer [1].

The adverse effect is mediated by a number of phenomena such as progression of atherosclerosis, endothelial dysfunction and increased oxidative stress with ultimate development of cardiovascular events [16-19]. Indeed, not all cases of hypertension and dyslipidemia are diagnosed and that management in a significant proportion of patients fails to accomplish target objectives [20,21]. Much is directed toward insulin resistance and lipid profile when dealing with metabolic syndrome and hypertension usually receive little if any attention [22]. Therefore, there is a need for a better approach to trace the coexistence of dyslipidemia and hypertension. The use of the term lipitension can offer better chance in identifying patients with dyslipidemia and hypertension [1]. Articles have admitted that the management of dyslipidemia, in particular low density lipoprotein lowering, has advantages on both cerebrovascular and coronary event rates, much more than blood pressure lowering alone [23]. On the other hand, blood pressure lowering has advantages both on the rates of cerebrovascular and coronary events [24].

\section{Conclusion}

In conclusion, the prevalence rate of simultaneous occurrence of dyslipidemia and hypertension is common in our community and there should be a program to detect those patients because higher risk of morbidity and mortality in such patients.

\section{References}

1. Dalal JJ, Padmanabhan TN, Jain P, Patil S, Vasnawala H, et al. (2012) Lipitension: Interplay between dyslipidemia and hypertension. Indian J Endocrinol Metab 16(2): 240-245.

2. Onesi SO, Ignatius UE (2014) Metabolic syndrome: Performance of five different diagnostic criterias. Indian J Endocrinol Metab. 18(4): 496-501.

3. Kopin L, Lowenstein C (2017) Dyslipidemia. Ann Intern Med 167(11): ITC81-ITC96.

4. Onat A, Hergenç G, Sari I, Türkmen S, Can G, et al. (2005) Dyslipidemic hypertension: distinctive features and cardiovascular risk in a prospective population-based study. Am J Hypertens 18(3): 409-416.

5. Expert Panel on Integrated Guidelines for Cardiovascular H, Risk Reduction in C, Adolescents, National Heart L, Blood I (2011) Expert panel on integrated guidelines for cardiovascular health and risk reduction in children and adolescents: summary report. Pediatrics 128 Suppl 5: S213-S256.

6. Kannel WB (2000) Fifty years of Framingham study contributions to understanding hypertension. J Hum Hypertens 14(2): 83-90.

7. Liao D, Mo J, Duan Y (2004) The Joint Effect of Hypertension and Elevated LDL-Cholesterol on CHD are beyond Additive (abstract) Eur Heart J 25(Suppl): 235.

8. Ginghina C, Bejan I, Ceck CD (2011) Modern risk stratification in coronary heart disease. J Med Life 4(4): 377-386.

9. Chobanian AV, Bakris GL, Black HR, Cushman WC, Green LA, et al. (2003) The Seventh Report of the Joint National Committee on Prevention, Detection, Evaluation, and Treatment of High Blood Pressure: The JNC 7 report. JAMA 289(19): 2560-2572.

10. Eaton B, Feldman A, Assaf R, McPhillips B, Hume L, et al. (1994) Prevalence of hypertension, dyslipidemia, and dyslipidemic hypertension. J FamPract 38(1): 17-23.

11. Mohan V, Deepa R, Rani SS, Premalatha G (2001) Prevalence of coronary artery disease and its relationship to lipids in a selected population in South India: The Chennai Urban Population Study (CUPS No. 5) J Am Coll Cardiol 38(3): 682-687.

12. Mohan V, Sandeep S, Deepa M, Gokulakrishnan K, Datta M, et al. (2007) A diabetes risk score helps identify metabolic syndrome and cardiovascular risk in Indians-The Chennai Urban Rural Epidemiology Study (CURES-38) Diabetes Obes Metab 9(3): 337-343.

13. Pemminati S, Prabha R, Pathak R, Pai R (2010) Prevalence of metabolic syndrome (METS) using IDF 2005 guidelines in a semi urban south Indian (Boloor Diabetes Study) population of Mangalore. J Assoc Physicians India 58: 674-677

14. Johnson ML, Pietz K, Battleman DS, Beyth RJ (2004) Prevalence of comorbidity hypertension and dyslipidemia and associated cardiovascular disease. Am J Manag Care 10(12): 926-932.

15. Expert Panel on Detection, Evaluation, and Treatment of High Blood Cholesterol in Adults (2001) Executive Summary of The Third Report of the National Cholesterol Education Program (NCEP) Expert Panel. Detection, evaluation and treatment of high blood cholesterol in adults (Adult Treatment Panel III). JAMA 285(19): 2486-2497.

16. Ross R (1999) Atherosclerosis an inflammatory disease. N Engl J Med 340(2): 115-126.

17. O'Donnell VB (2003) Free radicals and lipid signaling in endothelial cells. Antiox Redox Signal 5(2): 195-203. 
18. Wolfrum S, Jensen KS, Liao JK (2003) Endothelium-dependent effects of statins. Arterioscler Thromb Vasc Biol 23(5): 729-736.

19. Kaplan M, Aviram M (1999) Oxidized low density lipoprotein: atherogenic and proinflammatory characteristics during macrophage foam cell formation. An inhibitory role for nutritional antioxidants and serum paraoxonase. Clin Chem Lab Med 37(8): 777-787.

20. Sawant AM, Dhanashri S, Mankeshwar R, Tester A (2008) Prevalence of dyslipidemia in young adult Indian population. J Assoc Physicians India 56: 99-102.

21. Blaha MJ, Bansal S, Rouf R, Golden SH, Blumenthal RS, et al. (2008) Practical "ABCDE" approach to the metabolic syndrome. Mayo Clin Proc 83(8): 932-941.
22. Kasiske BL, Ma JZ, Kalil RS, Louis TA (1995) Effects of antihypertensive therapy on serum lipids. Ann Intern Med 122(2): 133-141.

23. Cardillo C, Kilcoyne CM, Cannon RO, Panza JA (2000) Increased activity of endogenous endothelin in patients with hypercholesterolemia. J Am Coll Cardiol 36(5): 1483-1488.

24. Kannel WB, Carter BL (1989) Initial drug therapy for hypertensive patients with Hyperlipidemia. Am Heart J 118: 1012-1021. 